\title{
Additives: Their Influence on the Humidity- and Pressure-Induced Crystallization of Amorphous $\mathrm{CaCO}_{3}$
}

\author{
Huachuan Du, Clemence Courrégelongue, Jacinta Xto, Alan Böhlen, Mathias Steinacher,
} Camelia N. Borca, Thomas Huthwelker, and Esther Amstad*

Cite This: Chem. Mater. 2020, 32, 4282-4291

Read Online

\section{ACCESS | Llll Metrics \& More | 回 Article Recommendations | (s) Supporting Information}

ABSTRACT: Nature possesses a unique control over the formation of $\mathrm{CaCO}_{3}$ crystals that imparts fascinating mechanical properties to many $\mathrm{CaCO}_{3}$-based biomaterials. This high level of control is, at least in part, achieved through the use of certain soluble additives that influence the crystallization of amorphous $\mathrm{CaCO}_{3}$ (ACC). Inspired by nature, excellent work has been performed to elucidate the influence of additives on the crystallization of ACC that is dispersed in bulk aqueous solutions or subjected to elevated temperatures. By contrast, very little is known about the influence of additives on the crystallization of ACC when exposed to a humid environment or elevated pressures. This incomplete understanding restricts the range of properties that can be obtained in synthetic $\mathrm{CaCO}_{3}$-based biomaterials. To address this shortcoming, we study the influence

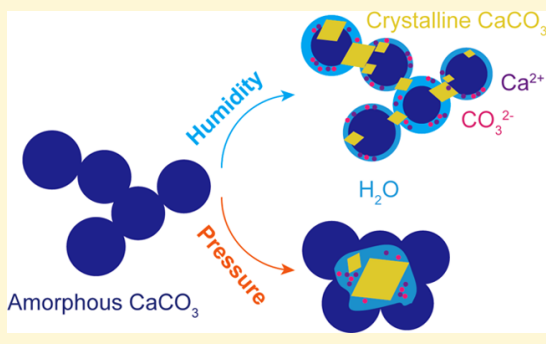
of additives on the humidity- and pressure-induced crystallization of ACC. We find that the humidity-induced crystallization of ACC follows a distinctly different pathway than the pressure-induced one. As a result, the influence of additives on the crystallization kinetics of ACC, and hence, the size, morphology, structure, and orientation of the resulting $\mathrm{CaCO}_{3}$ crystals, differs considerably. These insights offer new opportunities to design $\mathrm{CaCO}_{3}$-based biomaterials whose mechanical properties more closely resemble natural ones.

\section{INTRODUCTION}

Calcium carbonate is one of the most prevalent biominerals in nature. It displays excellent mechanical properties and hence is often used as a structural material, for example, to protect soft tissues. $^{1-3}$ The unique mechanical properties are a result of the well-defined size, morphology, structure, and orientation of $\mathrm{CaCO}_{3}$ crystals. $^{2-6}$ Natural $^{7-10}$ and synthetic ${ }^{11-16} \mathrm{CaCO}_{3}$ crystals typically form through the crystallization of a transient precursor, namely, ACC. The excellent control over the $\mathrm{CaCO}_{3}$ formation achieved by nature is, at least in part, due to its ability to use certain soluble additives, including $\mathrm{Mg}^{2+}$ ions and proteins containing carboxyl or phosphate groups, to tune the crystallization of ACC. ${ }^{4,10,17,18}$ Inspired by nature, a lot of research has been devoted to understanding the role of additives in the crystallization of ACC under different processing conditions. ${ }^{4,10,19-23}$ These studies are crucial for the development of new processes to fabricate $\mathrm{CaCO}_{3}$-based materials with well-defined structures and properties. ${ }^{19,24-30}$

Amorphous $\mathrm{CaCO}_{3}$ is metastable and hence crystallizes with time. $^{16,17,31,32}$ This crystallization can be accelerated if ACC particles are immersed in bulk solutions. ${ }^{12,13,15,16,20,33,34}$ In this case, they dissolve and result in an aqueous solution that is supersaturated with respect to crystalline $\mathrm{CaCO}_{3}$ from where new $\mathrm{CaCO}_{3}$ crystals form. . $^{12,15-17,20,34-36}$ This crystallization pathway offers limited control over the structure and properties of the resulting $\mathrm{CaCO}_{3}$ crystals. Crystallization of ACC can also be accelerated if particles are exposed to elevated temperatures $^{20,34,35,37-41}$ where ACC undergoes a solid-state transformation that includes a complete dehydration of ACC and a subsequent formation of $\mathrm{CaCO}_{3}$ crystals. ${ }^{17,20,34,35,37,39,42,43}$ These two crystallization pathways possess distinctly different activation energies, and hence, their crystallization kinetics differ. ${ }^{16,17,43-45}$ This discrepancy translates into differences in the size, morphology, and structure of the resulting $\mathrm{CaCO}_{3}$ crystals. ${ }^{17,34}$

The crystallization of ACC in bulk solutions or at elevated temperatures can be influenced by low molecular weight additives such as $\mathrm{Mg}^{2+},{ }^{41,46-49} \mathrm{PO}_{4}{ }^{3-},{ }^{40,41}$ citrate (CIT), ${ }^{22,50}$ glycine (Gly), ${ }^{51}$ and aspartic acid (Asp) $)^{51}$ as well as high molecular weight counterparts such as poly(acrylic acid) (PAA), ${ }^{12,23,42,52}$ poly(styrenesulfonate) (PSS), ${ }^{20,23,50,53-55}$ poly(aspartic acid) (PAsp), ${ }^{19,56}$ poly(allylamine hydro-chloride) (PAH), ${ }^{57,58}$ and acidic proteins. ${ }^{59-61}$ The effects of these additives on the crystallization of ACC depend on their molecular weight, ${ }^{20,62,63}$ functional groups, ${ }^{20,23,41,50,52,58}$ and concentration. $^{21-23,46-48}$ Interestingly, the effects of certain additives also depend on the processing conditions. ${ }^{17,20}$ For

Received: March 5, 2020

Revised: April 16, 2020

Published: April 17, 2020 
example, the functionalization of ACC with PSS and PAsp increases its stability against crystallization if dispersed in bulk solutions but decreases it if exposed to elevated temperatures. $^{20,39}$

The crystallization of ACC can also be induced if it is exposed to a humid environment ${ }^{16,32,35,41,64,65}$ or elevated pressures. ${ }^{6,67}$ Remarkably, the stability of ACC against crystallization induced by pressure or humidity is distinctly different from that induced by temperature or humid environments. ${ }^{16,32,35,41,64,66,67}$ Similarly, the size, morphology, and structure of the resulting crystals depend on the crystallization pathway. This finding might open up new possibilities to fabricate $\mathrm{CaCO}_{3}$-based materials with structures and hence, properties that can be tuned over a much wider range. ${ }^{66,68}$ However, the effects of additives on the crystallization of ACC induced by humid environments or elevated pressures are poorly understood. $\mathrm{Mg}^{2+41,64}$ and $\mathrm{PO}_{4}{ }^{3-41}$ have been shown to increase the kinetic stability of ACC against humidity-induced crystallization. However, the influence of other additives on the humidity-induced crystallization and that of additives on the pressure-induced crystallization are unknown. This incomplete understanding limits the range of structures and properties of $\mathrm{CaCO}_{3}$-based materials that can be accessed. To fill this gap, a better understanding of the influence of additives on the humidityand pressure-induced crystallization of ACC and how these parameters relate to the size, structure, and morphology of the resulting crystals is needed.

Here, we study the influence of different additives on the crystallization of ACC when exposed to a humid environment or elevated pressures. We monitor the evolution of the structure and degree of hydration of ACC during its crystallization in situ and ex situ and relate these results to the size, morphology, structure, and orientation of the resulting crystals. We find that the humidity-induced ACC crystallization pathway is distinctly different from the pressureinduced counterpart. Hence, additives influence the stability of ACC against crystallization as well as the size, morphology, structure, and orientation of the resulting $\mathrm{CaCO}_{3}$ crystals differently. These new insights might offer new possibilities to design $\mathrm{CaCO}_{3}$-based materials whose structures and mechanical properties can be tuned to more closely resemble those of natural counterparts.

\section{EXPERIMENTS}

Synthesis of Additive-Functionalized ACC Particles. We employ a variety of additives that are often used to control the crystallization of ACC in bulk solutions to tune the stability of ACC against pressure- and humidity-induced crystallization, as summarized in Figure S1. ${ }^{12,20,22,23,41,46,51,57,58}$ To compare the influence of different additives on the crystallization of ACC, we fix the molar ratio of the low molecular weight additives, including glycine (Gly), citric acid (CIT), acrylic acid (AA), and magnesium chloride hexahydrate $(\mathrm{Mg})$ to $\mathrm{Ca}^{2+}$ present in the initial solution to $1: 10$. Similarly, we keep the molar ratio of the repeat units of the polymeric additives, such as poly(acrylic acid) (PAA-15K and PAA-450K), poly(sodium 4-styrenesulfonate) (PSS-70K), and poly(allylamine) (PAL-15K) to $\mathrm{Ca}^{2+}$ present in the initial solution to $1: 10$. An aqueous solution $(1.75 \mathrm{~mL})$ containing $1 \mathrm{M} \mathrm{CaCl}_{2}$ is mixed with an aqueous solution $(1.75 \mathrm{~mL})$ containing additives for $10 \mathrm{~min}$ using an ultrasonic bath. In addition, $3.5 \mathrm{~mL}$ of an aqueous solution containing $0.5 \mathrm{M} \mathrm{Na}_{2} \mathrm{CO}_{3}$ is prepared. All solutions are stored at $4{ }^{\circ} \mathrm{C}$ for at least $2 \mathrm{~h}$. The solution containing $0.5 \mathrm{M} \mathrm{Na}_{2} \mathrm{CO}_{3}$ is added to the solution containing $\mathrm{CaCl}_{2}$ and additives and vortexed for $10 \mathrm{~s}$. To quench the precipitation reaction, $40 \mathrm{~mL}$ of cold ethanol $\left(4{ }^{\circ} \mathrm{C}\right)$ is added $30 \mathrm{~s}$ after the reaction has been initiated and the mixture is again vortexed for $10 \mathrm{~s}$. To extract the precipitates, the mixture is centrifuged at 4500 $\mathrm{rpm}$ for $5 \mathrm{~min}$ at $4{ }^{\circ} \mathrm{C}$ before the supernatant is removed. The resulting ACC particles are washed twice, each time with $35 \mathrm{~mL}$ of ethanol, before the ACC particles are dried and stored in a vacuum desiccator. In addition, we synthesize CIT-functionalized ACC with a three-fold lower CIT concentration using the same protocol. To synthesize unfunctionalized ACC particles as controls, we prepare 3.5 $\mathrm{mL}$ of an aqueous solution containing $0.5 \mathrm{M} \mathrm{CaCl}_{2}$ and mix it with $3.5 \mathrm{~mL}$ of an aqueous solution containing $0.5 \mathrm{M} \mathrm{Na}_{2} \mathrm{CO}_{3}$. All the following steps are identical to those described for the synthesis of additive-functionalized ACC. The structural characteristics of assynthesized ACC particles are investigated with Fourier Transform infrared spectroscopy (FTIR) and X-ray diffraction (XRD), as shown in Figure S2.

Humidity-Induced Crystallization of ACC. To perform the humidity-induced crystallization experiments, we deposit a layer of ACC powder on an aluminum tape that is glued to the bottom of a humidity chamber. We supply $20 \mathrm{~mL} \cdot \mathrm{min}^{-1} \mathrm{~N}_{2}$ to the humidity chamber to keep the relative humidity ( $\mathrm{RH}$ ) constant around $95 \%$.

Pressure-Induced Crystallization of ACC. The pressureinduced crystallization experiments are performed at room temperature using a PressPRO programmable hydraulic press (PIKE Technologies). We employ a cylindrical die with an inner diameter of $13 \mathrm{~mm}$ that is typically used for pressing $\mathrm{KBr}$ pellets for FTIR measurements. We add approximately $30 \mathrm{mg}$ of the ACC powder to the pellet die and subject the powder to well-defined pressures. In the first sets of experiments, we subject samples to pressures between 87 and $738 \mathrm{MPa}$ for $30 \mathrm{~min}$ to induce their crystallization. Additivefunctionalized ACC samples that do not crystallize at $738 \mathrm{MPa}$ within $30 \mathrm{~min}$, which is the highest pressure that can be applied with this setup, are subjected to a pressure of $738 \mathrm{MPa}$ for an extended pressing time to induce the crystallization.

Characterization. Fourier Transform Infrared Spectroscopy. To monitor the crystallization kinetics of ACC subjected to a humid environment in situ, we place the humidity chamber under a Hyperion 3000 Fourier Transform infrared microscope (Bruker) and measure the sample using an Invenio FTIR spectrometer (Bruker). Spectra are measured from 650 to $4000 \mathrm{~cm}^{-1}$ with a resolution of $4 \mathrm{~cm}^{-1}$ in the reflection mode. For each measurement, 60 scans are averaged. For samples characterized ex situ, FTIR spectra are acquired using a Nicolet 6700 FTIR spectrometer (ThermoFisher Scientific) operated in the attenuated total reflection (ATR) mode. Spectra are acquired from 650 to $4000 \mathrm{~cm}^{-1}$ with a resolution of $4 \mathrm{~cm}^{-1}$. For each measurement, 32 scans are averaged.

$X$-Ray Diffraction. XRD patterns are acquired using an Empyrean diffractometer (Malvern Panalytical) with a $\mathrm{Cu} \mathrm{K} \alpha$ radiation $(\lambda=$ $1.5406 \AA$ ). The samples are deposited on glass slides (Corning). The diffraction patterns are collected within a $2 \theta$ range of $10^{\circ}$ to $50^{\circ}$ and at a scanning rate of $0.1^{\circ} \cdot \mathrm{s}^{-1}$. Crystalline peaks are identified with the HighScore Plus software.

Thermogravimetric Analysis (TGA). TGA measurements are recorded on a TGA 4000 instrument (Perkin Elmer). For each measurement, approximately $5 \mathrm{mg}$ of ACC powder is placed into an alumina crucible. The crucible is heated from 30 to $800^{\circ} \mathrm{C}$ at a rate of $10{ }^{\circ} \mathrm{C} \cdot \mathrm{min}^{-1}$ under a flow of dry nitrogen whose rate is kept constant at $20 \mathrm{~mL} \cdot \mathrm{min}^{-1}$.

Scanning Electron Microscopy (SEM). The size and morphology of amorphous and crystallized samples are characterized with a field emission SEM (Zeiss Merlin). The SEM is operated at an acceleration voltage of $6 \mathrm{kV}$ and a probe of $100 \mathrm{pA}$. Images are acquired with a secondary electron detector. All the samples are coated with a $20 \mathrm{~nm}$ thick Au:Pd (80:20) film to avoid charging effects.

Transmission Electron Microscopy (TEM). To check the orientation of $\mathrm{CaCO}_{3}$ crystals obtained from the humidity-induced crystallization, the crystalline sample is characterized using a Talos TEM (FEI). The TEM is operated using an acceleration voltage of $200 \mathrm{kV}$. The condenser aperture 1 is $2000 \mu \mathrm{m}$, and the condenser aperture 2 is $100 \mu \mathrm{m}$. SAED patterns are collected using a $10 \mu \mathrm{m}$ aperture. To prepare the samples, ACC particles are dispersed in 

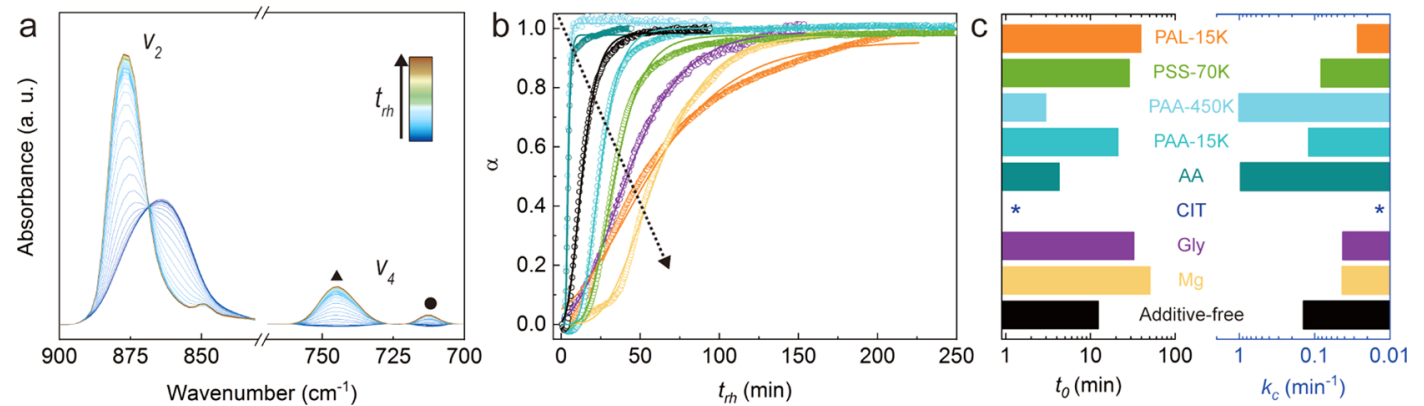

Figure 1. Crystallization kinetics of ACC particles if exposed to a relative humidity (RH) around 95\%. (a) Time-resolved FTIR spectra of AAfunctionalized ACC measured in situ when exposed to the high humidity for $44 \mathrm{~min}$. The baselines of these spectra are subtracted. The $\nu_{4}$ peaks corresponding to vaterite are indicated by a triangle, and those corresponding to calcite are indicated by a circle. (b) Degree of crystallization $(\alpha)$ as a function of the exposure time $\left(t_{\mathrm{rh}}\right)$. The values extracted from the time-resolved in situ FTIR measurements are indicated with empty symbols and the fits with solid lines. In the direction of the arrow, the traces correspond to ACC particles functionalized with PAA-450K, AA, unfunctionalized ACC, and ACC functionalized with PAA-15K, PSS-70K, Gly, PAL-15K, and Mg. (c) Induction time $\left(t_{0}\right)$ and crystallization rate coefficient $\left(k_{\mathrm{c}}\right)$ of ACC obtained by fitting the traces of $\alpha$ as a function of time $(t)$ with the Gompertz model. There is no sign of crystallization of CIT-functionalized ACC within $6 \mathrm{~h}$ such that we could not determine these values for it.

ethanol and deposited onto a carbon film-coated copper grid before ethanol evaporates. The grid is subsequently placed in the humidity chamber to crystallize the ACC particles.

\section{RESULTS}

Humidity-Induced Crystallization. To monitor the kinetics of the humidity-induced crystallization of ACC particles, we expose them to a $\mathrm{N}_{2}$-based atmosphere possessing a $\mathrm{RH}$ around $95 \%$ and measure their structure using timeresolved in situ FTIR. While particles are exposed to such a high humidity, the $\nu_{2}$ peak around $874 \mathrm{~cm}^{-1}$ and the $\nu_{4}$ peaks between 700 and $750 \mathrm{~cm}^{-1}$, characteristic for crystalline $\mathrm{CaCO}_{3}$, appear, as exemplified for AA-functionalized ACC in Figure $1 \mathrm{a}$ and unfunctionalized ACC in Figure S6. The intensity of these peaks increases with increasing exposure time $\left(t_{\mathrm{rh}}\right)$ until it levels off, whereas the intensity of the $\nu_{2}$ peak around $863 \mathrm{~cm}^{-1}$, characteristic for ACC, gradually decreases until it disappears. These results are in good agreement with reports on the crystallization of unfunctionalized ACC particles exposed to a humid environment ${ }^{35}$ or water drops. ${ }^{69}$

To determine the crystallization kinetics of ACC, we extract the degree of crystallization $(\alpha)$, defined as the ratio of the crystallized to the initial ACC, from time-resolved in situ FTIR data and plot them as a function of $t_{\mathrm{rh}}$, as shown in Figure $1 \mathrm{~b}$ and detailed in the Supporting Information. To quantitatively describe the crystallization kinetics, we fit each trace with the Gompertz model, $\ln \alpha=-e^{\left[-k_{c}\left(t-t_{0}\right)\right]}$, which has previously been used to describe the humidity-induced crystallization kinetics. ${ }^{64}$ From these fits, we extract the induction time $\left(t_{0}\right)$ and the crystallization rate coefficient $\left(k_{c}\right)$, as summarized in Figure 1c. The functionalization of ACC with AA and PAA$450 \mathrm{~K}$ decreases $t_{0}$ and increases $k_{\mathcal{O}}$ indicating that these additives decrease the kinetic stability of ACC against the humidity-induced crystallization. By contrast, the functionalization of ACC with $\mathrm{Mg}$, Gly, PAA-15K, PSS-70K, and PAL$15 \mathrm{~K}$ increases $t_{0}$ and decreases $k_{\mathcal{c}}$, indicating that these additives increase the kinetic stability of ACC. CIT increases the stability of ACC even more: these particles do not crystallize even if exposed to the same humid environment for as long as $30 \mathrm{~h}$, more than 10 times the time other ACC particles have been exposed to this environment, as shown in Figure S5. The high stability of CIT-functionalized ACC against the humidity-induced crystallization is well in agree- ment with what has been observed for CIT-stabilized ACC exposed to bulk solutions. ${ }^{22,51}$ To reduce the stability of CITfunctionalized ACC, we lower the CIT concentration 3-fold. Even in this case, these particles only start to crystallize after 12 $h$, as shown in the FTIR results in Figure S7. These results indicate that the kinetic stability of ACC against humidityinduced crystallization can be tuned by functionalizing it with additives, by analogy to the crystallization induced in bulk solutions or through the exposure to elevated temperatures.

To test if the molecular weight of additives influences the kinetic stability of ACC particles, we functionalize them with AA monomers, PAA-15K, and PAA-450K. Indeed, these particles display different kinetic stabilities: PAA-15K increases the kinetic stability of ACC, whereas AA and PAA-450K reduce it, as shown in Figure 1c.

To test if the composition of the functional groups of additives influences the kinetic stability of ACC, we produce particles functionalized with PAL and PAA with an average molecular weight of 15,000 Da. PAL-15K-functionalized particles are more stable against humidity-induced crystallization than their PAA-15K-functionalized counterparts. Similarly, the kinetic stabilities for ACC particles functionalized with low molecular weight additives with similar molecular weights, namely, AA, Gly, Mg, and CIT, differ, as summarized in Figure 1c. These results suggest that the kinetic stability of additive-functionalized ACC against humidityinduced crystallization depends on the composition of the functional groups and the molecular weight of the additives, in good agreement with the results obtained for additivefunctionalized ACC particles that are exposed to bulk solutions $^{20,23,52,62}$ or elevated temperatures. ${ }^{20,23,41}$

The kinetic stability of ACC against the humidity-induced crystallization has been shown to increase with decreasing degree of hydration $(n)$ of $\mathrm{ACC}\left(\mathrm{CaCO}_{3} \cdot n \mathrm{H}_{2} \mathrm{O}\right) .{ }^{41}$ To test if the observed differences in the kinetic stability of ACC are related to variations in $n$, we quantify $n$ using TGA. The degrees of hydration for most ACC particles synthesized here are around 1, as shown in Figure S3, in good agreement with literature. $^{34,70}$ These results indicate that the observed differences in the kinetic stability cannot be attributed to different degrees of hydration of ACC particles.

The kinetic stability of ACC particles has been shown to increase slightly with decreasing size. ${ }^{41}$ To test if additives 

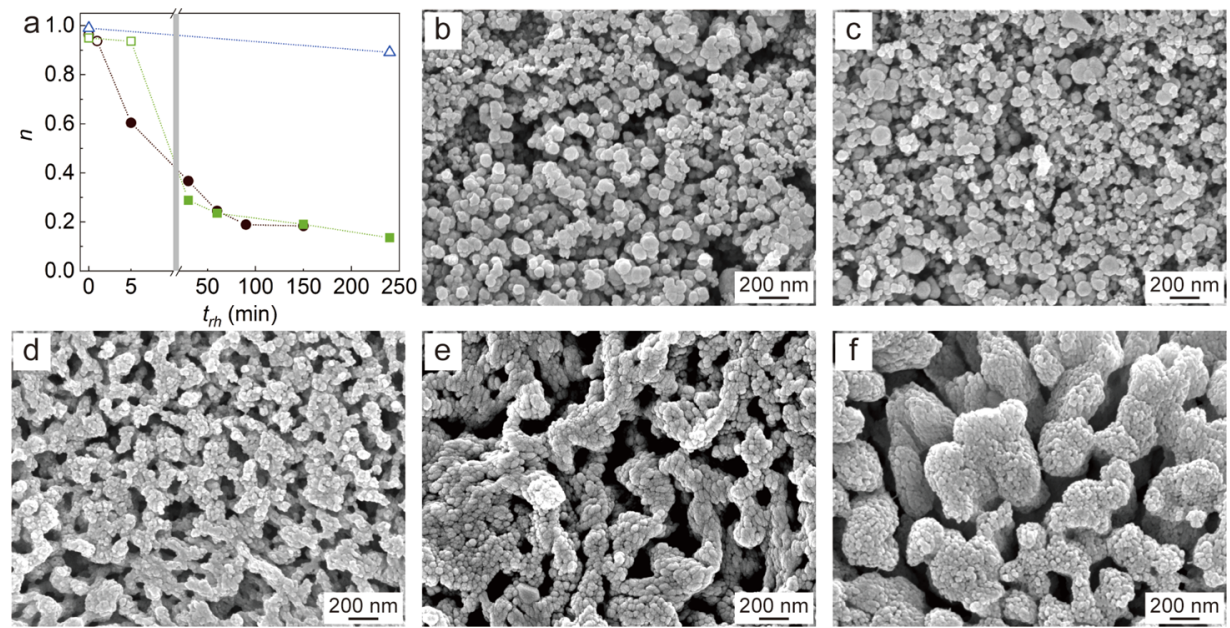

Figure 2. Evolution of the degree of hydration $(n)$ and morphology of ACC particles if exposed to a RH around $95 \%$. (a) $n$ for unfunctionalized ACC particles (black circle) and those functionalized with PSS-70K (green square) and CIT (blue triangle) as a function of $t_{\mathrm{rh}}$, quantified using TGA. Samples that, according to ex situ FTIR measurements, remain amorphous are indicated with empty symbols, those containing crystalline $\mathrm{CaCO}_{3}$ with solid symbols. (b-f) SEM images of ACC particles functionalized with PSS-70K after having been exposed to a humid environment for (b) 0, (c) 5, (d) 30, (e) 150, and (f) $240 \mathrm{~min}$.

studied here influence the size of ACC particles, we quantify this parameter using SEM, as shown in Figure S4. The size and size distribution of the ACC particles investigated here are very similar. These results suggest that the measured difference in the kinetic stability cannot be caused by varying particle sizes.

The humidity-induced crystallization has been suggested to occur through a surface-coupled partial dissolution-reprecipitation pathway where water contained in the environment is adsorbed on the surface of ACC and partially dissolves it. $^{16,17,32,35,41,64}$ Thereby, a supersaturated solution forms from which $\mathrm{CaCO}_{3}$ crystals can start to precipitate. ${ }^{16,17,32,35,41,64}$ The partial dissolution-reprecipitation process has been proposed to be initiated only if a significant amount of water has been adsorbed on the surface of ACC. ${ }^{32,64}$ To check if additives studied here influence the amount of water adsorbed on the surfaces of ACC particles, we measure $n$ as a function of $t_{\mathrm{rh}}$ using TGA, as exemplified in Figure S8a. The degree of hydration does not significantly increase for any of the tested samples during the induction stage, as shown in Figure 2a. Similarly, the morphology of these particles remains the same, as shown in SEM images in Figure $2 b, c$ and Figure S8b,c. These results indicate that only very small amounts of water are adsorbed on the surface of ACC before crystallization starts. Once ACC starts to transform into an anhydrous crystal through a partial dissolution-reprecipitation process, the remaining water associated with ACC, which accounts for the majority of the water initially contained in ACC, is expelled. This expelled water accelerates the crystallization of adjacent ACC particles, as shown in Figures $1 \mathrm{~b}$ and 2a. During this process, particles merge, thereby increasing the average particle size, as shown in Figure $2 \mathrm{~d}-\mathrm{f}$ and Figure S8d-f. These results suggest that different additives influence the kinetics of the humidity-induced crystallization of ACC by modifying the kinetics of the partial dissolution-reprecipitation rather than the water adsorption. ${ }^{17,41}$

Crystals Obtained from the Humidity-Induced Crystallization. Many additives influence the structure of $\mathrm{CaCO}_{3}$ crystals that form through the crystallization of ACC in bulk solutions. ${ }^{17}$ To test if this is also the case for crystals formed by exposing ACC to a humid environment, we determine their structures as a function of the type of additives present in ACC with FTIR. Unfunctionalized ACC and ACC functionalized with Gly, AA, PAA-15K, and PAA-450K crystallize into a mixture of vaterite and calcite, as indicated by the presence of a $\nu_{4}$ absorption peak around the $744 \mathrm{~cm}^{-1}$ characteristic for vaterite and that around the $712 \mathrm{~cm}^{-1}$ characteristic for calcite, as shown in Figure 3a. ACC functionalized with $\mathrm{Mg}$, CIT, and PAL-15K predominantly transforms into calcite, as suggested by the presence of the $\nu_{4}$ absorption peak around $712 \mathrm{~cm}^{-1}$ and the absence of the $\nu_{4}$ absorption peak around $744 \mathrm{~cm}^{-1}$. By contrast, ACC functionalized with PSS-70K predominantly transforms into vaterite, as suggested by the presence of the $\nu_{4}$ absorption peak around $744 \mathrm{~cm}^{-1}$ and the absence of that around $712 \mathrm{~cm}^{-1}$.

To check if the differences in the structure of $\mathrm{CaCO}_{3}$ translate into morphological variations, we image the formed $\mathrm{CaCO}_{3}$ crystals with SEM. All the samples that transformed into a mixture of vaterite and calcite are composed of loosely packed nanocrystals and do not possess any well-defined facets, as exemplified in Figure $3 \mathrm{~b}-\mathrm{d}$. By contrast, crystals formed from ACC functionalized with $\mathrm{Mg}$ and CIT that mainly possess the calcite structure have a truncated rhombohedral morphology, as shown in Figure 3e,f. These results indicate that only selected additives influence the structure and morphology of the $\mathrm{CaCO}_{3}$ crystals formed in humid environments. Interestingly, many $\mathrm{CaCO}_{3}$ nanocrystals contained in agglomerates display a similar orientation, as indicated by their morphology in Figure 3 and Figure S9 and confirmed by the selected area electron diffraction pattern (SAED) in the inset of Figure 3g. These results are in good agreement with those reported for the humidity-induced crystallization of unfunctionalized ACC and ACC functionalized with $\mathrm{Mg}^{16,64}$

Pressure-Induced Crystallization. The crystallization of ACC can also be induced without the addition of water, for example, if it is subjected to elevated pressures. ${ }^{66,67}$ To study the influence of additives on the kinetics of the pressureinduced crystallization, we subject ACC to well-defined uniaxial pressures for $30 \mathrm{~min}$. We measure the structure of the resulting samples ex situ using FTIR and XRD. 


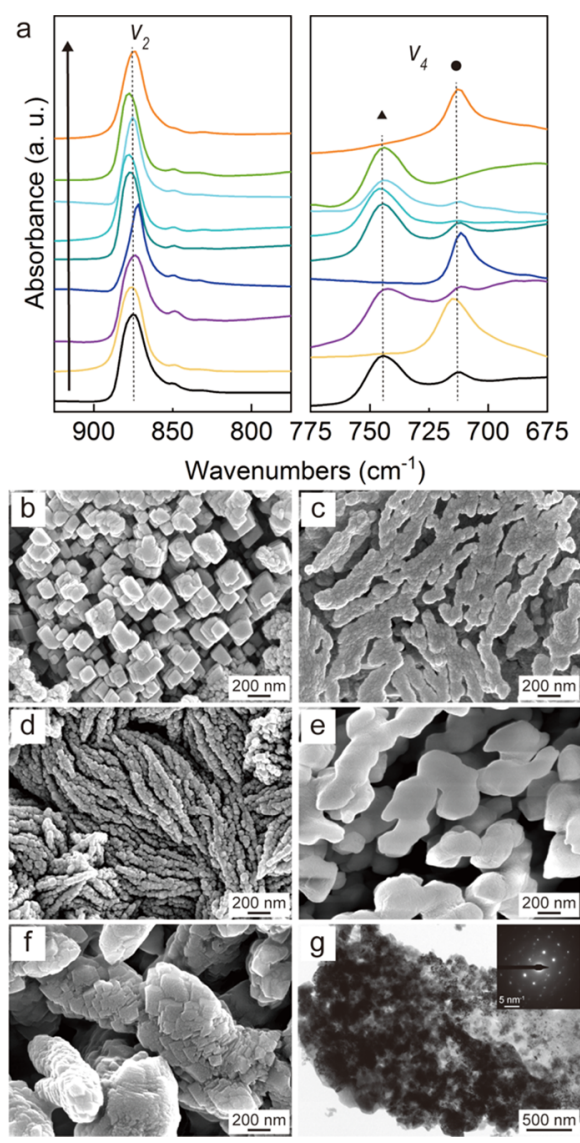

Figure 3. Structure, size, morphology, and orientation of $\mathrm{CaCO}_{3}$ crystals formed by exposing ACC to a humid environment. (a) FTIR spectra of $\mathrm{CaCO}_{3}$ crystals obtained from unfunctionalized ACC (bottom) and ACC functionalized with $\mathrm{Mg}$, Gly, CIT, AA, PAA-15K, PAA-450K, PSS-70K, and PAL-15K (in the direction of the arrow). The $\nu_{4}$ peaks corresponding to vaterite are indicated by a triangle, and those corresponding to calcite are indicated by a circle. (b-e) SEM images of $\mathrm{CaCO}_{3}$ crystals obtained from (b, c) unfunctionalized ACC and ACC functionalized with (d) PAA-15K, (e) Mg, and (f) CIT. (g) Transmission electron microscopy (TEM) image of $\mathrm{CaCO}_{3}$ crystals obtained from unfunctionalized ACC with the selected area electron diffraction (SAED) pattern as the inset.

The kinetic stability of ACC against pressure-induced crystallization also depends on the additive: unfunctionalized ACC has a critical pressure $\left(P_{c}\right)$, defined as the pressure where it starts to crystallize if exposed to it for $30 \mathrm{~min}$, of $222 \mathrm{MPa}$, as indicated by the shift of the $\nu_{2}$ absorption peak from 863 to $874 \mathrm{~cm}^{-1}$ and the appearance of two $\nu_{4}$ absorption peaks around 712 and $744 \mathrm{~cm}^{-1}$ in Figure $4 a, b$. The kinetic stability of ACC increases if functionalized with $\mathrm{Mg}$, Gly, and PAA$15 \mathrm{~K}$, as summarized in Figure $4 \mathrm{c}$. The kinetic stability of ACC increases even more if it is functionalized with CIT, PSS-70K, and PAL-15K: these particles do not crystallize within $30 \mathrm{~min}$ even if subjected to $738 \mathrm{MPa}$, as shown in Figure S10, and only crystallize if subjected to this high pressure for a prolonged time $\left(t_{c}\right)$, as summarized in Figure $4 \mathrm{~d}$. Other additives decrease the kinetic stability of ACC. For example, $P_{c}$ of ACC functionalized with PAA-450K is as low as $87 \mathrm{MPa}$. Yet, other additives, such as AA, do not measurably change the kinetic stability of ACC. These results indicate that the molecular weight of additives strongly influences the kinetic stability of ACC. This parameter also depends on the composition of the functional group: $P_{c}$ and $t_{c}$ for ACC
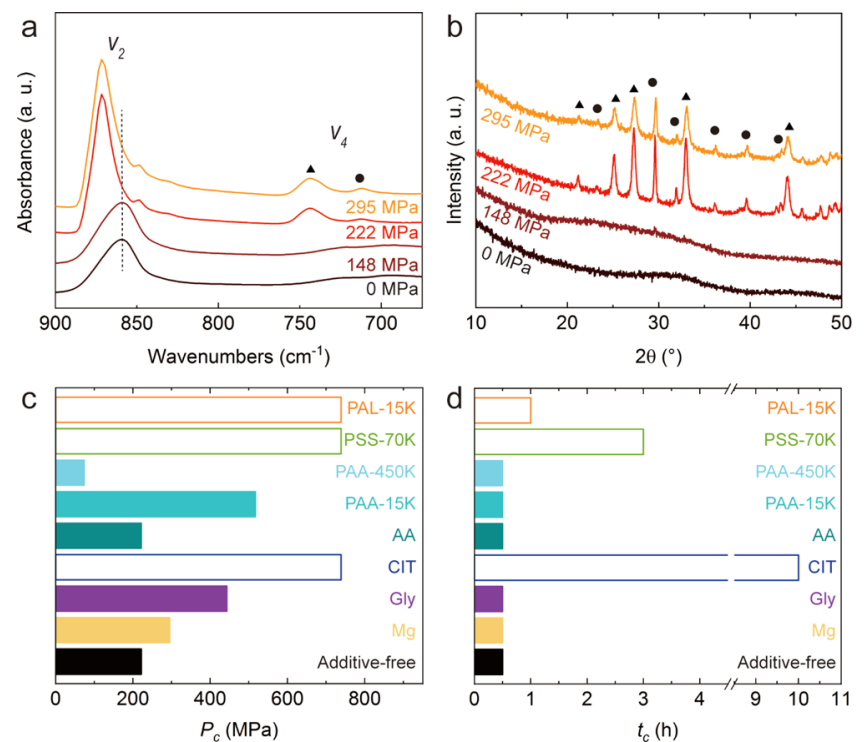

Figure 4. Crystallization kinetics of ACC particles if subjected to elevated pressures. (a) FTIR traces and (b) XRD patterns of AAfunctionalized ACC after having been exposed to different pressures for $30 \mathrm{~min}$. Features corresponding to vaterite are indicated by triangles and those corresponding to calcite by circles. (c) Comparison of critical pressures $\left(P_{c}\right)$ of ACC functionalized with different additives. Samples possessing a $P_{\mathrm{c}}$ above $738 \mathrm{MPa}$, the maximum pressure that our experimental setup can achieve, are indicated as empty bars. (d) Comparison of critical time $\left(t_{c}\right)$ required to crystallize ACC if subjected to a pressure of $738 \mathrm{MPa}$. Samples that crystallize within $30 \mathrm{~min}$ are indicated as solid bars.

particles functionalized with $\mathrm{AA}, \mathrm{Gly}, \mathrm{Mg}$, and $\mathrm{CIT}$ vary significantly, even though the molecular weights of these additives are similar, as shown in Figure $4 c$,d. The kinetic stability of ACC against pressure-induced crystallization does not scale with $n$ or the particle size, as a comparison between Figure 4 and Figure S3 and Figure 4 and Figure S4 reveals, by analogy to what we observe for the humidity-induced crystallization.

The pressure-induced crystallization of ACC has been thought to occur through a solid-state transformation, although experimental evidence is missing. ${ }^{67}$ If this was the case, then ACC must be fully dehydrated before crystals can start to form, by analogy to the temperature-induced crystallization. ${ }^{17,20,35,41-43}$ To test if this is the case, we quantify the evolution of $n$ for ACC that has been subjected to $738 \mathrm{MPa}$ for different durations using TGA, as shown in Figure S11. To obtain a high temporal resolution, we quantify the evolution of $n$ of ACC that crystallizes slowly, namely, ACC functionalized with PAL-15K, PSS-70K, and CIT. CIT-functionalized ACC only starts to crystallize after $10 \mathrm{~h}$. Yet, we observe a decrease in $n$ from 1 to 0.82 within the first hour and a plateau thereafter, as illustrated in Figure 5a. We obtain similar results for the other two samples. These results indicate that ACC partially dehydrates while being exposed to elevated pressures, consistent with the results previously reported for unfunctionalized ACC. ${ }^{71}$ These results suggest that ACC subjected to elevated pressures only partially dehydrates before it starts to crystallize, in stark contrast to the full dehydration that occurs in the temperature-induced solid-state transformation. ${ }^{17,35,41,43}$

Dehydration of ACC is kinetically controlled by its activation energy that is determined by the interaction strength between water and ions contained in ACC. ${ }^{17,42,43,45,72}$ During 

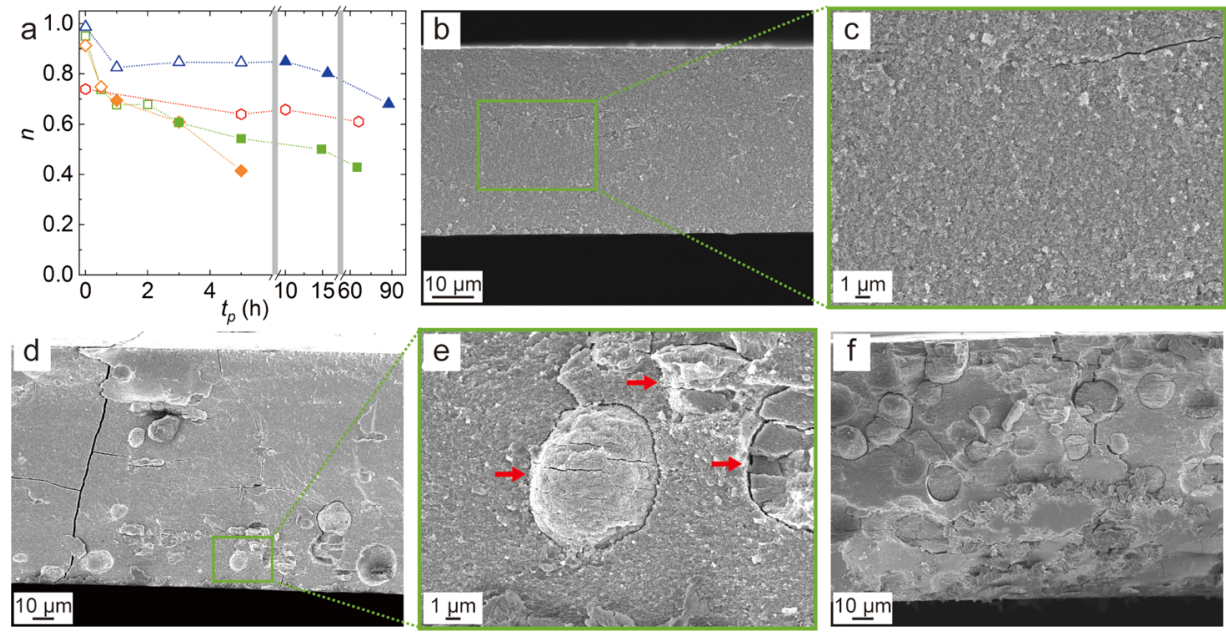

Figure 5. Evolution of $n$ and the morphology of ACC particles if subjected to a pressure of $738 \mathrm{MPa}$. (a) $n$ for ACC functionalized with PAL-15K (orange diamond), PSS-70K (green square), CIT (blue triangle), and PSS-70K that has been annealed at $100{ }^{\circ} \mathrm{C}$ for $10 \mathrm{~min}$ (red hexagon) as a function of the time they have been exposed to $738 \mathrm{MPa}\left(t_{\mathrm{p}}\right)$, measured using TGA. Samples that remain amorphous are indicated with empty symbols, crystallized ones with solid symbols. $(\mathrm{b}-\mathrm{f})$ Cross-section SEM images of compacted films obtained by pressing ACC functionalized with PSS-70K at $738 \mathrm{MPs}$ for (b, c) $10 \mathrm{~min}$, (d, e) $10 \mathrm{~h}$, and (f) $68 \mathrm{~h}$. The $\mathrm{CaCO}_{3}$ crystals in panel e are indicated with arrows.

the pressure-induced crystallization, the weakly interacting mobile water is expelled before the crystallization is initiated. However, the pressure is insufficient to expel the strongly interacting, rigid water such that it is only removed during the crystallization of ACC. If the pressure-induced crystallization occurs through dissolution-reprecipitation, ${ }^{16,43}$ the activation energy for pressure-induced crystallization would be lower compared to that for the temperature-induced one. To check if the humidity in ambient air triggers a dissolution-reprecipitation process that drives the pressure-induced crystallization studied here, we expose unfunctionalized ACC particles to ambient air that has a $\mathrm{RH}$ around 50\% without applying any pressure and measure their crystallization kinetics ex situ with FTIR. We cannot detect any sign of crystallization even after the particles have been exposed to this environment for $56 \mathrm{~h}$, more than 100 times longer than the duration needed to crystallize particles at elevated pressures, as a comparison between Figure S12 and Figure 4c,d reveals. This observation indicates that the humidity of ambient air does not measurably influence our pressure-induced crystallization results. Instead, the dissolution-reprecipitation process is most likely initiated by the mobile water that is released during the partial dehydration of ACC particles under elevated pressures. In line with this expectation, we observe large crystals in the interior of compact films composed of dehydrated ACC particles, as exemplified in SEM images in Figure $5 b-f$.

If the pressure-induced crystallization of ACC follows a dissolution-reprecipitation process, we expect its kinetics to depend on the amount of mobile water contained in ACC. To test this expectation, we compare the time required to initiate crystallization of ACC functionalized with CIT with that of ACC functionalized with PSS-70K or PAL-15K that contain much more mobile water, as shown in Figure 5a. Indeed, the time required to initiate the crystallization of CIT-functionalized ACC particles is significantly longer, as exemplified in Figure $4 \mathrm{~d}$. To further test our hypothesis, we remove the mobile water contained in PSS-70K-functionalized ACC particles by annealing them at $100{ }^{\circ} \mathrm{C}$ in a $\mathrm{N}_{2}$ atmosphere for $10 \mathrm{~min}$ and subject these particles to $738 \mathrm{MPa}$. Indeed, we do not observe any sign of crystallization even after having exposed these particles to such a high pressure for $66 \mathrm{~h}$, a duration that is more than 20-fold longer than $t_{c}$ measured for their nonannealed counterparts, as shown in Figure 5a and Figure S13. This clear difference confirms that the pressureinduced crystallization is initiated by the mobile water that is released from ACC particles when pressurized. These results suggest that additives influence the kinetic stability of ACC against the pressure-induced crystallization because they interact with mobile water, thereby changing the ease to remove it.

Crystals Obtained from the Pressure-Induced Crystallization. To test if additives influence the structure of $\mathrm{CaCO}_{3}$ crystals that form through the pressure-induced crystallization of ACC, we characterize the resulting crystals using FTIR. Crystalline samples obtained from unfunctionalized ACC and ACC functionalized with Gly, AA, PAA-15K, PAA-450K, PSS-70K, and PAL-15K are composed of a mixture of vaterite and calcite, as shown in Figure 6a. By contrast, ACC functionalized with $\mathrm{Mg}$ and CIT predominantly transforms into calcite.

To relate the crystalline structure to the morphology of the formed crystals, we visualize them with SEM. All samples are composed of heavily agglomerated $\mathrm{CaCO}_{3}$ nanocrystals whose size varies from a few hundreds of nanometers to tens of micrometers, as shown in Figure $6 \mathrm{~b}-\mathrm{e}$ and Figure S14. The vast majority of crystals contained in these samples does not display any well-defined facets, and only a few crystals possess the characteristic rhombohedral morphology of calcite, as exemplified in Figure $6 \mathrm{~b}-\mathrm{d}$. By contrast, Mg-functionalized ACC that transforms into calcite attains the truncated rhombohedral morphology characteristic for this crystal structure, as shown in Figure 6e. These results suggest that certain additives can influence the structure, size, and morphology of $\mathrm{CaCO}_{3}$ crystals obtained from the pressureinduced crystallization of ACC by analogy to what we observed for the humidity-induced crystallization.

\section{DISCUSSION}

Kinetic Stability of ACC. The composition of the functional groups of additives and their molecular weight 

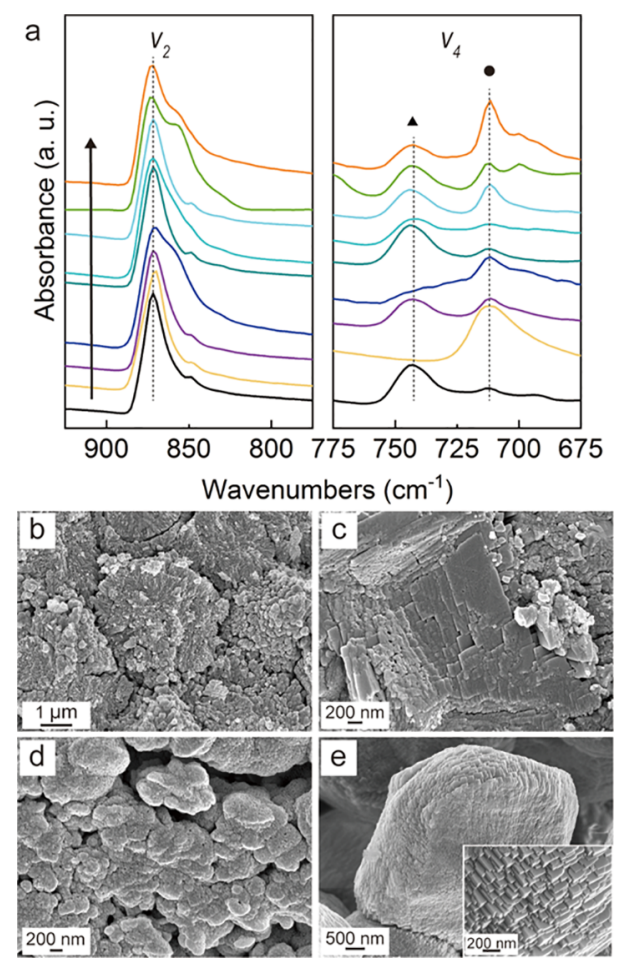

Figure 6. Structure, size, and morphology of $\mathrm{CaCO}_{3}$ crystals formed through pressure-induced crystallization. (a) FTIR spectra of $\mathrm{CaCO}_{3}$ crystals obtained from unfunctionalized ACC (bottom) and ACC functionalized with $\mathrm{Mg}$, Gly, CIT, AA, PAA-15K, PAA-450K, PSS$70 \mathrm{~K}$, and PAL-15K (in the direction of the arrow). (b-e) SEM images of $\mathrm{CaCO}_{3}$ crystals formed through the crystallization of $(b, c)$ unfunctionalized ACC and ACC functionalized with (d) CIT and (e) $\mathrm{Mg}$.

influence the kinetic stability of ACC against the humidity- and pressure-induced crystallization. However, the effect of certain additives on the stability of ACC against crystallization is distinctly different for these two crystallization processes, as a comparison between Figures 1 and 4 reveals. For example, while Mg-functionalized ACC displays a higher kinetic stability against the humidity-induced crystallization than ACC functionalized with Gly, PAA-15K, or PSS-70K, it shows a lower kinetic stability against the pressure-induced crystallization. A similar process-dependent effect of additives on the stability of ACC against crystallization has been reported if ACC particles were exposed to bulk water or elevated temperatures. $^{20,39}$ In this case, this discrepancy was attributed to differences in the crystallization pathways. By analogy, the difference in the effects of additives observed here indicate that ACC crystallizes through different pathways if exposed to a humid environment or elevated pressures.

During the humidity-induced crystallization, water contained in the humid environment is adsorbed on the surfaces of ACC particles and partially dissolves them such that $\mathrm{CaCO}_{3}$ crystals form from a supersaturated solution in close proximity of the particle surface, as illustrated in Figure 7a,b. In this case, we demonstrate that the kinetic stability of ACC against crystallization mainly depends on that of the partial dissolution-reprecipitation and hence, on the mobility of water associated with ACC particles. ${ }^{17,32,41,64}$ If no additives are contained in ACC, the mobility of water is mainly determined by the degree of hydration of $\mathrm{ACC}^{17,41,42}$ and the amount of water contained in the surrounding environ-

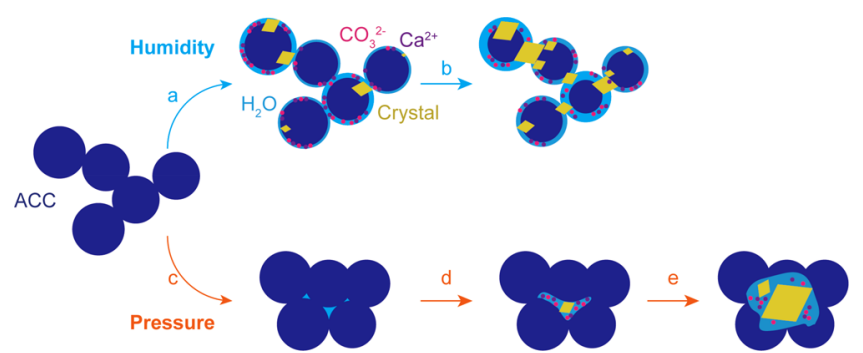

Figure 7. Schematic illustration of the crystallization pathways of the humidity- and pressure-induced crystallization of ACC. (a, b) The humidity-induced crystallization follows a surface-coupled partial dissolution-reprecipitation pathway. (a) Water contained in the humid environment is adsorbed on the surfaces of ACC particles where it initiates the partial dissolution of ACC that is followed by the formation crystals. (b) Once ACC starts to transform into anhydrous crystals, additional water contained in ACC is released and accelerates the dissolution-reprecipitation process. $(\mathrm{c}-\mathrm{e})$ The pressure-induced crystallization follows a dehydration-assisted local dissolutionprecipitation pathway. (c) While being compressed, ACC particles start to dehydrate. (d) The released mobile water accumulates in certain regions of the film composed of dehydrated ACC particles where it initiates a local dissolution-reprecipitation process. (e) Once ACC starts to transform into anhydrous crystals, rigid water is released from partially dehydrated ACC and accelerates the dissolution-reprecipitation process.

ment. $^{23,32,35,64}$ If ACC is functionalized with certain additives, such as $\mathrm{Mg}^{2+},{ }^{26,73} \mathrm{PO}_{4}{ }^{3-},{ }^{40} \mathrm{PSS}^{74}{ }^{74 A}{ }^{42,74}$ and Asp-rich proteins, ${ }^{75}$ the mobility of water is also influenced by its interaction with these additives. In this case, the kinetics of the partial dissolution-reprecipitation process depends on the interaction strength between additives and water. ${ }^{41,64}$ Because the tested additives do not significantly change the degree of hydration of ACC and we keep the humidity constant, we assign the observed differences in the crystallization kinetics primarily to the different interaction strengths of these additives with water. Indeed, the interaction strength of CIT with water is stronger than that of other tested additives, such as PSS-70K and PAL-15K, resulting in a smaller amount of mobile water contained in ACC particles, as shown in Figure 5a. An additional contribution might come from certain additives such as $\mathrm{CIT},{ }^{76,77} \mathrm{Mg}^{2+},{ }^{78,79}$ and $\mathrm{Gly}^{51}$ that inhibit the nucleation or growth of $\mathrm{CaCO}_{3}$ crystals by adsorbing on their surfaces. ${ }^{20}$ These factors likely are important reasons for the very high stability of CIT-functionalized ACC against crystallization even if the $\mathrm{CIT} / \mathrm{Ca}^{2+}$ ratio is reduced 3-fold.

During the pressure-induced crystallization, mobile water is released from ACC and accumulates in certain regions of the compressed film where it locally initiates a full dissolutionreprecipitation process, as shown in Figure $7 c-e$. In this case, both the kinetics of the dehydration and that of the dissolution-reprecipitation are determined by the amount of mobile water contained in these particles. Additives studied here have different interaction strengths with water ${ }^{17,42,73}$ such that they display different effects on the kinetic stability of ACC against pressure-induced crystallization.

Size, Morphology, Orientation, and Crystalline Structure of $\mathrm{CaCO}_{3}$ Crystals. Our results demonstrate that the size and morphology of $\mathrm{CaCO}_{3}$ crystals formed through the humidity-induced crystallization of ACC differs from that obtained from the pressure-induced crystallization. $\mathrm{CaCO}_{3}$ crystals formed through a humidity-induced crystallization are typically composed of loosely packed nanoparticles with 
diameters of a few hundreds of nanometers; these particles closely resemble as-synthesized ACC particles. By contrast, $\mathrm{CaCO}_{3}$ crystals obtained from the pressure-induced crystallization are typically microsized agglomerates composed of densely packed nanoparticles. This difference is likely caused by the varying amounts of water present during the crystallization of ACC. During the humidity-induced crystallization, a limited number of water molecules is adsorbed on the surfaces of ACC particles and dissolves them only partially. ${ }^{16,32}$ The small volume of the resulting supersaturated solution confines the crystals ${ }^{35,64}$ and results in a slow growth such that these crystals display a preferential orientation. ${ }^{16,64,68}$ By contrast, during the pressure-induced crystallization, ACC particles form a compacted film. The released mobile water molecules accumulate in certain regions of this film and locally initiate the dissolution of particles. The larger volume of the supersaturated solution enables crystals to rapidly form and grow such that they attain a morphology and size that is similar to those formed in bulk solutions.

The effects of additives on the structure of crystals obtained from the humidity- and pressure-induced crystallization depend on the composition of their functional groups and the processing conditions. For example, functionalization of ACC with $\mathrm{Mg}$ and CIT favors the formation of calcite if ACC is subjected to a humid environment or elevated pressures, in line with results reported for the crystallization in bulk solutions. $^{22,46}$ By contrast, the structure of crystals formed from PSS-70K-functionalized ACC depends on the processing conditions: it predominantly transforms into vaterite if crystallized under humid conditions, whereas it transforms into a mixture of vaterite and calcite if subjected to elevated pressures. Similarly, ACC functionalized with PAL-15K predominantly transforms into calcite if subjected to humid environments and into a mixture of vaterite and calcite if subjected to elevated pressures. This process-dependent behavior is likely related to the differences in the local supersaturations and the crystallization kinetics that exist in the two crystallization processes. ${ }^{32,34}$ These examples demonstrate possibilities to tune the size, morphology, orientation, and structure of $\mathrm{CaCO}_{3}$ crystals with processing conditions without altering their composition.

\section{CONCLUSIONS}

We show that the size, morphology, structure, and orientation of $\mathrm{CaCO}_{3}$ crystals formed from certain additive-functionalized ACC depend on the crystallization conditions. We assign the process-dependent behavior to the different pathways through which ACC crystallizes that influence the crystallization kinetics: the humidity-induced crystallization of ACC follows a surface-coupled partial dissolution-reprecipitation where crystallization is spatially confined. By contrast, the pressureinduced crystallization undertakes a dehydration-assisted local dissolution-reprecipitation that is much less confined. In both cases, additives influence the kinetics of different steps of the ACC crystallization through their interaction with water, as schematically illustrated in Figure 7 . These insights provide new opportunities to more closely control the formation of $\mathrm{CaCO}_{3}$ crystals and hence, the properties of $\mathrm{CaCO}_{3}$-based materials by using appropriate additives and tuning the processing conditions to crystallize ACC.

\section{ASSOCIATED CONTENT}

\section{Supporting Information}

The Supporting Information is available free of charge at https://pubs.acs.org/doi/10.1021/acs.chemmater.0c00975.

Experimental details and methods to calculate the degree of hydration of ACC samples from TGA measurements, protocols to estimate the degree of crystallization during the humidity-induced crystallization from the in situ FTIR data, and Figures S1 to S14 (PDF)

\section{AUTHOR INFORMATION}

\section{Corresponding Author}

Esther Amstad - Soft Materials Laboratory, Institute of Materials, Ecole Polytechnique Féderale de Lausanne (EPFL), 1015 Lausanne, Switzerland; ㅇo orcid.org/0000-0002-94911010; Email: esther.amstad@epfl.ch

\section{Authors}

Huachuan Du - Soft Materials Laboratory, Institute of Materials, Ecole Polytechnique Féderale de Lausanne (EPFL), 1015 Lausanne, Switzerland; 이이.org/0000-0002-16844430

Clemence Courrégelongue - Soft Materials Laboratory, Institute of Materials, Ecole Polytechnique Féderale de Lausanne (EPFL), 1015 Lausanne, Switzerland; Département de Chimie, Ecole Normale Supérieure, PSL University, 75005 Paris, France

Jacinta Xto - Swiss Light Source, Paul Scherrer Institute, 5232 Villigen, Switzerland; (ㅇ) orcid.org/0000-0001-6448-7207

Alan Böhlen - Soft Materials Laboratory, Institute of Materials, Ecole Polytechnique Féderale de Lausanne (EPFL), 1015

Lausanne, Switzerland

Mathias Steinacher - Soft Materials Laboratory, Institute of Materials, Ecole Polytechnique Féderale de Lausanne (EPFL), 1015 Lausanne, Switzerland

Camelia N. Borca - Swiss Light Source, Paul Scherrer Institute, 5232 Villigen, Switzerland

Thomas Huthwelker - Swiss Light Source, Paul Scherrer Institute, 5232 Villigen, Switzerland

Complete contact information is available at:

https://pubs.acs.org/10.1021/acs.chemmater.0c00975

\section{Notes}

The authors declare no competing financial interest.

\section{ACKNOWLEDGMENTS}

We thank Ziyu Zhao, Luca Vergano, Aysu Ceren Okur, and Dr. Wenhua Bi for their experimental help. We acknowledge the Swiss Light Source, Paul Scherrer Institute, Villigen, Switzerland for providing the infrastructure and support for performing the time-resolved in situ FTIR at the IR beamline. This work was financially supported by the Swiss National Center of Competence in Research (NCCR) Bio-Inspired Materials.

\section{REFERENCES}

(1) Wegst, U. G. K.; Bai, H.; Saiz, E.; Tomsia, A. P.; Ritchie, R. O. Bioinspired Structural Materials. Nat. Mater. 2015, 14, 23-36.

(2) Du, H.; Steiner, U.; Amstad, E. Nacre-Inspired Hard and Tough Materials. Chim. Int. J. Chem. 2019, 73, 29-34.

(3) Eder, M.; Amini, S.; Fratzl, P. Biological Composites-Complex Structures for Functional Diversity. Science 2018, 362, 543-547. 
(4) Gower, L. B. Biomimetic Model Systems for Investigating the Amorphous Precursor Pathway and Its Role in Biomineralization. Chem. Rev. 2008, 108, 4551-4627.

(5) Sommerdijk, N. A. J. M.; de With, G. Biomimetic $\mathrm{CaCO}_{3}$ Mineralization Using Designer Molecules and Interfaces. Chem. Rev. 2008, 108, 4499-4550.

(6) Meldrum, F. C.; Cölfen, H. Controlling Mineral Morphologies and Structures in Biological and Synthetic Systems. Chem. Rev. 2008, 108, 4332-4432.

(7) Beniash, E.; Aizenberg, J.; Addadi, L.; Weiner, S. Amorphous Calcium Carbonate Transforms into Calcite during Sea Urchin Larval Spicule Growth. Proc. R. Soc. B Biol. Sci. 1997, 264, 461-465.

(8) Politi, Y.; Arad, T.; Klein, E.; Weiner, S.; Addadi, L. Sea Urchin Spine Calcite Forms via a Transient Amorphous Calcium Carbonate Phase. Science 2004, 306, 1161-1164.

(9) Killian, C. E.; Metzler, R. A.; Gong, Y. U. T.; Olson, I. C.; Aizenberg, J.; Politi, Y.; Wilt, F. H.; Scholl, A.; Young, A.; Doran, A.; Kunz, M.; Tamura, N.; Coppersmith, S. N.; Gilbert, P. U. P. A. Mechanism of Calcite Co-Orientation in the Sea Urchin Tooth. J. Am. Chem. Soc. 2009, 131, 18404-18409.

(10) Addadi, L.; Raz, S.; Weiner, S. Taking Advantage of Disorder: Amorphous Calcium Carbonate and Its Roles in Biomineralization. Adv. Mater. 2003, 15, 959-970.

(11) Clarkson, J. R.; Price, T. J.; Adams, C. J. Role of Metastable Phases in the Spontaneous Precipitation of Calcium Carbonate. J. Chem. Soc., Faraday Trans. 1992, 88, 243-249.

(12) Rieger, J.; Thieme, J.; Schmidt, C. Study of Precipitation Reactions by X-ray Microscopy: $\mathrm{CaCO}_{3}$ Precipitation and the Effect of Polycarboxylates. Langmuir 2000, 16, 8300-8305.

(13) Pontoni, D.; Bolze, J.; Dingenouts, N.; Narayanan, T.; Ballauff, M. Crystallization of Calcium Carbonate Observed In-Situ by Combined Small- and Wide-Angle X-Ray Scattering. J. Phys. Chem. B 2003, 107, 5123-5125.

(14) Meldrum, F. C. Calcium Carbonate in Biomineralisation and Biomimetic Chemistry. Int. Mater. Rev. 2003, 48, 187-224.

(15) Rodriguez-Blanco, J. D.; Shaw, S.; Benning, L. G. The Kinetics and Mechanisms of Amorphous Calcium Carbonate (ACC) Crystallization to Calcite, Viavaterite. Nanoscale 2011, 3, 265-271.

(16) Rodriguez-Navarro, C.; Kudłacz, K.; Cizer, Ö.; Ruiz-Agudo, E. Formation of Amorphous Calcium Carbonate and Its Transformation into Mesostructured Calcite. CrystEngComm 2015, 17, 58-72.

(17) Du, H.; Amstad, E. Water: How Does It Influence the $\mathrm{CaCO}_{3}$ Formation? Angew. Chem. Int. Ed. 2020, 59, 1798-1816.

(18) Cölfen, H. Precipitation of Carbonates: Recent Progress in Controlled Production of Complex Shapes. Curr. Opin. Colloid Interface Sci. 2003, 8, 23-31.

(19) Gower, L. B.; Odom, D. J. Deposition of Calcium Carbonate Films by a Polymer-Induced Liquid-Precursor (PILP) Process. J. Cryst. Growth 2000, 210, 719-734.

(20) Ihli, J.; Kim, Y.-Y.; Noel, E. H.; Meldrum, F. C. The Effect of Additives on Amorphous Calcium Carbonate (ACC): Janus Behavior in Solution and the Solid State. Adv. Funct. Mater. 2013, 23, 15751585.

(21) Zou, Z.; Bertinetti, L.; Politi, Y.; Fratzl, P.; Habraken, W. J. E. M. Control of Polymorph Selection in Amorphous Calcium Carbonate Crystallization by Poly(Aspartic Acid): Two Different Mechanisms. Small 2017, 13, 1603100.

(22) Tobler, D. J.; Rodriguez-Blanco, J. D.; Dideriksen, K.; Bovet, N.; Sand, K. K.; Stipp, S. L. S. Citrate Effects on Amorphous Calcium Carbonate (ACC) Structure, Stability, and Crystallization. Adv. Funct. Mater. 2015, 25, 3081-3090.

(23) Xu, X.-R.; Cai, A.-H.; Liu, R.; Pan, H.-H.; Tang, R.-K.; Cho, K. The Roles of Water and Polyelectrolytes in the Phase Transformation of Amorphous Calcium Carbonate. J. Cryst. Growth 2008, 310, 37793787.

(24) Aizenberg, J.; Muller, D. A.; Grazul, J. L.; Hamann, D. R. Direct Fabrication of Large Micropatterned Single Crystals. Science 2003, 299, 1205-1208.
(25) Cantaert, B.; Kuo, D.; Matsumura, S.; Nishimura, T.; Sakamoto, T.; Kato, T. Use of Amorphous Calcium Carbonate for the Design of New Materials. ChemPlusChem 2017, 82, 107-120.

(26) Zeng, M.; Kim, Y.-Y.; Anduix-Canto, C.; Frontera, C.; Laundy, D.; Kapur, N.; Christenson, H. K.; Meldrum, F. C. Confinement Generates Single-Crystal Aragonite Rods at Room Temperature. Proc. Natl. Acad. Sci. 2018, 115, 7670-7675.

(27) Finnemore, A.; Cunha, P.; Shean, T.; Vignolini, S.; Guldin, S.; Oyen, M.; Steiner, U. Biomimetic Layer-by-Layer Assembly of Artificial Nacre. Nat. Commun. 2012, 3, 966.

(28) Kim, Y.-Y.; Carloni, J. D.; Demarchi, B.; Sparks, D.; Reid, D. G.; Kunitake, M. E.; Tang, C. C.; Duer, M. J.; Freeman, C. L.; Pokroy, B.; Penkman, K.; Harding, J. H.; Estroff, L. A.; Baker, S. P.; Meldrum, F. C. Tuning Hardness in Calcite by Incorporation of Amino Acids. Nat. Mater. 2016, 15, 903-910.

(29) Mao, L.-B.; Gao, H.-L.; Yao, H.-B.; Liu, L.; Colfen, H.; Liu, G.; Chen, S.-M.; Li, S.-K.; Yan, Y.-X.; Liu, Y.-Y.; Yu, S.-H. Synthetic Nacre by Predesigned Matrix-Directed Mineralization. Science 2016, 354, 107-110.

(30) Sun, S.; Mao, L.-B.; Lei, Z.; Yu, S.-H.; Cölfen, H. Hydrogels from Amorphous Calcium Carbonate and Polyacrylic Acid: BioInspired Materials for "Mineral Plastics.". Angew. Chem. Int. Ed. 2016, 55, 11765-11769.

(31) Ihli, J.; Kulak, A. N.; Meldrum, F. C. Freeze-Drying Yields Stable and Pure Amorphous Calcium Carbonate (ACC). Chem. Commun. 2013, 49, 3134.

(32) Konrad, F.; Gallien, F.; Gerard, D. E.; Dietzel, M. Transformation of Amorphous Calcium Carbonate in Air. Cryst. Growth Des. 2016, 16, 6310-6317.

(33) Bots, P.; Benning, L. G.; Rodriguez-Blanco, J.-D.; RoncalHerrero, T.; Shaw, S. Mechanistic Insights into the Crystallization of Amorphous Calcium Carbonate (ACC). Cryst. Growth Des. 2012, 12, 3806-3814.

(34) Zou, Z.; Bertinetti, L.; Politi, Y.; Jensen, A. C. S.; Weiner, S.; Addadi, L.; Fratzl, P.; Habraken, W. J. E. M. Opposite Particle Size Effect on Amorphous Calcium Carbonate Crystallization in Water and during Heating in Air. Chem. Mater. 2015, 27, 4237-4246.

(35) Xu, X.; Han, J. T.; Kim, D. H.; Cho, K. Two Modes of Transformation of Amorphous Calcium Carbonate Films in Air. J. Phys. Chem. B 2006, 110, 2764-2770.

(36) Wang, Y.-W.; Kim, Y.-Y.; Stephens, C. J.; Meldrum, F. C.; Christenson, H. K. In Situ Study of the Precipitation and Crystallization of Amorphous Calcium Carbonate (ACC). Cryst. Growth Des. 2012, 12, 1212-1217.

(37) Koga, N.; Nakagoe, Y.; Tanaka, H. Crystallization of Amorphous Calcium Carbonate. Thermochim. Acta 1998, 318, 239244.

(38) Radha, A. V.; Forbes, T. Z.; Killian, C. E.; Gilbert, P. U. P. A.; Navrotsky, A. Transformation and Crystallization Energetics of Synthetic and Biogenic Amorphous Calcium Carbonate. Proc. Natl. Acad. Sci. 2010, 107, 16438-16443.

(39) Noel, E. H.; Kim, Y.-Y.; Charnock, J. M.; Meldrum, F. C. Solid State Crystallization of Amorphous Calcium Carbonate Nanoparticles Leads to Polymorph Selectivity. CrystEngComm 2013, 15, 697-705.

(40) Kababya, S.; Gal, A.; Kahil, K.; Weiner, S.; Addadi, L.; Schmidt, A. Phosphate-Water Interplay Tunes Amorphous Calcium Carbonate Metastability: Spontaneous Phase Separation and Crystallization vs Stabilization Viewed by Solid State NMR. J. Am. Chem. Soc. 2015, 137, 990-998.

(41) Albéric, M.; Bertinetti, L.; Zou, Z.; Fratzl, P.; Habraken, W.; Politi, Y. The Crystallization of Amorphous Calcium Carbonate Is Kinetically Governed by Ion Impurities and Water. Adv. Sci. 2018, 5, 1701000.

(42) Du, H.; Steinacher, M.; Borca, C.; Huthwelker, T.; Murello, A.; Stellacci, F.; Amstad, E. Amorphous $\mathrm{CaCO}_{3}$ : Influence of the Formation Time on Its Degree of Hydration and Stability. J. Am. Chem. Soc. 2018, 140, 14289-14299.

(43) Ihli, J.; Wong, W. C.; Noel, E. H.; Kim, Y.-Y.; Kulak, A. N.; Christenson, H. K.; Duer, M. J.; Meldrum, F. C. Dehydration and 
Crystallization of Amorphous Calcium Carbonate in Solution and in Air. Nat. Commun. 2014, 5, 1-10.

(44) Saharay, M.; Yazaydin, A. O.; Kirkpatrick, R. J. DehydrationInduced Amorphous Phases of Calcium Carbonate. J. Phys. Chem. B 2013, 117, 3328-3336.

(45) Bushuev, Y. G.; Finney, A. R.; Rodger, P. M. Stability and Structure of Hydrated Amorphous Calcium Carbonate. Cryst. Growth Des. 2015, 15, 5269-5279.

(46) Loste, E.; Wilson, R. M.; Seshadri, R.; Meldrum, F. C. The Role of Magnesium in Stabilising Amorphous Calcium Carbonate and Controlling Calcite Morphologies. J. Cryst. Growth 2003, 254, 206218.

(47) Blue, C. R.; Giuffre, A.; Mergelsberg, S.; Han, N.; De Yoreo, J. J.; Dove, P. M. Chemical and Physical Controls on the Transformation of Amorphous Calcium Carbonate into Crystalline $\mathrm{CaCO}_{3}$ Polymorphs. Geochim. Cosmochim. Acta 2017, 196, 179-196.

(48) Radha, A. V.; Fernandez-Martinez, A.; Hu, Y.; Jun, Y.-S.; Waychunas, G. A.; Navrotsky, A. Energetic and Structural Studies of Amorphous $\mathrm{Ca}_{1-\mathrm{x}} \mathrm{Mg}_{\mathrm{x}} \mathrm{CO}_{3} \cdot \mathrm{nH}_{2} \mathrm{O} \quad(0 \leqslant \mathrm{x} \leqslant 1)$. Geochim. Cosmochim. Acta 2012, 90, 83-95.

(49) Xto, J. M.; Du, H.; Borca, C. N.; Amstad, E.; van Bokhoven, J. A.; Huthwelker, T. Tuning the Incorporation of Magnesium into Calcite during Its Crystallization from Additive-Free Aqueous Solution. Cryst. Growth Des. 2019, 19, 4385-4394.

(50) Verch, A.; Gebauer, D.; Antonietti, M.; Cölfen, H. How to Control the Scaling of $\mathrm{CaCO}_{3}$ : A "Fingerprinting Technique" to Classify Additives. Phys. Chem. Chem. Phys. 2011, 13, 16811-16820.

(51) Tobler, D. J.; Blanco, J. D. R.; Dideriksen, K.; Sand, K. K.; Bovet, N.; Benning, L. G.; Stipp, S. L. S. The Effect of Aspartic Acid and Glycine on Amorphous Calcium Carbonate (ACC) Structure, Stability and Crystallization. Procedia Earth and Planetary Science 2014, 10, 143-148.

(52) Gebauer, D.; Cölfen, H.; Verch, A.; Antonietti, M. The Multiple Roles of Additives in $\mathrm{CaCO}_{3}$ Crystallization: A Quantitative Case Study. Adv. Mater. 2009, 21, 435-439.

(53) Smeets, P. J. M.; Cho, K. R.; Kempen, R. G. E.; Sommerdijk, N. A. J. M.; De Yoreo, J. J. Calcium Carbonate Nucleation Driven by Ion Binding in a Biomimetic Matrix Revealed by in Situ Electron Microscopy. Nat. Mater. 2015, 14, 394-399.

(54) Wang, T.; Cölfen, H.; Antonietti, M. Nonclassical Crystallization: Mesocrystals and Morphology Change of $\mathrm{CaCO}_{3}$ Crystals in the Presence of a Polyelectrolyte Additive. J. Am. Chem. Soc. 2005, 127, 3246-3247.

(55) Wang, T.; Antonietti, M.; Cölfen, H. Calcite Mesocrystals: "Morphing" Crystals by a Polyelectrolyte. Chem. - Eur. J. 2006, 12, 5722-5730.

(56) Lam, R. S. K.; Charnock, J. M.; Lennie, A.; Meldrum, F. C. Synthesis-Dependant Structural Variations in Amorphous Calcium Carbonate. CrystEngComm 2007, 9, 1226-1236.

(57) Cantaert, B.; Kim, Y.-Y.; Ludwig, H.; Nudelman, F.; Sommerdijk, N. A. J. M.; Meldrum, F. C. Think Positive: Phase Separation Enables a Positively Charged Additive to Induce Dramatic Changes in Calcium Carbonate Morphology. Adv. Funct. Mater. 2012, 22, 907-915.

(58) Schenk, A. S.; Cantaert, B.; Kim, Y.-Y.; Li, Y.; Read, E. S.; Semsarilar, M.; Armes, S. P.; Meldrum, F. C. Systematic Study of the Effects of Polyamines on Calcium Carbonate Precipitation. Chem. Mater. 2014, 26, 2703-2711.

(59) Wolf, S. E.; Leiterer, J.; Pipich, V.; Barrea, R.; Emmerling, F.; Tremel, W. Strong Stabilization of Amorphous Calcium Carbonate Emulsion by Ovalbumin: Gaining Insight into the Mechanism of "Polymer-Induced Liquid Precursor" Processes. J. Am. Chem. Soc. 2011, 133, 12642-12649.

(60) Ruiz-Agudo, C.; Lutz, J.; Keckeis, P.; King, M.; Marx, A.; Gebauer, D. Ubiquitin Designer Proteins as a New Additive Generation toward Controlling Crystallization. J. Am. Chem. Soc. 2019, 141, 12240-12245.
(61) Rao, A.; Drechsler, M.; Schiller, S.; Scheffner, M.; Gebauer, D.; Cölfen, H. Stabilization of Mineral Precursors by Intrinsically Disordered Proteins. Adv. Funct. Mater. 2018, 28, 1802063.

(62) Huang, S.-C.; Naka, K.; Chujo, Y. Effect of Molecular Weights of Poly(Acrylic Acid) on Crystallization of Calcium Carbonate by the Delayed Addition Method. Polym. J. 2008, 40, 154-162.

(63) Xu, A.-W.; Ma, Y.; Cölfen, H. Biomimetic Mineralization. J. Mater. Chem. 2007, 17, 415-449.

(64) Huang, Y.-C.; Gindele, M. B.; Knaus, J.; Rao, A.; Gebauer, D. On Mechanisms of Mesocrystal Formation: Magnesium Ions and Water Environments Regulate the Crystallization of Amorphous Minerals. CrystEngComm 2018, 20, 4395-4405.

(65) Xto, J. M.; Borca, C. N.; van Bokhoven, J. A.; Huthwelker, T. Aerosol-Based Synthesis of Pure and Stable Amorphous Calcium Carbonate. Chem. Commun. 2019, 55, 10725-10728.

(66) Yoshino, T.; Maruyama, K.; Kagi, H.; Nara, M.; Kim, J. C. Pressure-Induced Crystallization from Amorphous Calcium Carbonate. Cryst. Growth Des. 2012, 12, 3357-3361.

(67) Maruyama, K.; Kagi, H.; Inoue, T.; Ohfuji, H.; Yoshino, T. In Situ Observation of Pressure-Induced Crystallization from Amorphous Calcium Carbonate by Time-Resolved X-Ray Diffraction. Chem. Lett. 2015, 44, 434-436.

(68) Jehannin, M.; Rao, A.; Cölfen, H. New Horizons of NonClassical Crystallization. J. Am. Chem. Soc. 2019, 141, 10120-10136.

(69) Farhadi Khouzani, M.; Chevrier, D. M.; Güttlein, P.; Hauser, K.; Zhang, P.; Hedin, N.; Gebauer, D. Disordered Amorphous Calcium Carbonate from Direct Precipitation. CrystEngComm 2015, $17,4842-4849$.

(70) Gebauer, D.; Gunawidjaja, P. N.; Ko, J. Y. P.; Bacsik, Z.; Aziz, B.; Liu, L.; Hu, Y.; Bergström, L.; Tai, C.-W.; Sham, T.-K.; Edén, M.; Hedin, N. Proto-Calcite and Proto-Vaterite in Amorphous Calcium Carbonates. Angew. Chem. Int. Ed. 2010, 49, 8889-8891.

(71) Fernandez-Martinez, A.; Kalkan, B.; Clark, S. M.; Waychunas, G. A. Pressure-Induced Polyamorphism and Formation of 'Aragonitic' Amorphous Calcium Carbonate. Angew. Chem. Int. Ed. 2013, 52, 8354-8357.

(72) Goodwin, A. L.; Michel, F. M.; Phillips, B. L.; Keen, D. A.; Dove, M. T.; Reeder, R. J. Nanoporous Structure and Medium-Range Order in Synthetic Amorphous Calcium Carbonate. Chem. Mater. 2010, 22, 3197-3205.

(73) Koishi, A.; Fernandez-Martinez, A.; Ruta, B.; Jimenez-Ruiz, M.; Poloni, R.; di Tommaso, D.; Zontone, F.; Waychunas, G. A.; MontesHernandez, G. Role of Impurities in the Kinetic Persistence of Amorphous Calcium Carbonate: A Nanoscopic Dynamics View. J. Phys. Chem. C 2018, 122, 16983-16991.

(74) Sinn, C. G.; Dimova, R.; Antonietti, M. Isothermal Titration Calorimetry of the Polyelectrolyte/Water Interaction and Binding of $\mathrm{Ca}^{2+}$ : Effects Determining the Quality of Polymeric Scale Inhibitors. Macromolecules 2004, 37, 3444-3450.

(75) Politi, Y.; Mahamid, J.; Goldberg, H.; Weiner, S.; Addadi, L. Asprich Mollusk Shell Protein: In Vitro Experiments Aimed at Elucidating Function in $\mathrm{CaCO}_{3}$ Crystallization. CrystEngComm 2007, 9, 1171-1177.

(76) Montanari, G.; Rodriguez-Blanco, J. D.; Bovet, N.; Stipp, S. L. S.; Tobler, D. J. Impact of Citrate Ions on the Nucleation and Growth of Anhydrous $\mathrm{CaCO}_{3}$. Cryst. Growth Des. 2017, 17, 5269-5275.

(77) Westin, K.-J.; Rasmuson, Å. C. Nucleation of Calcium Carbonate in Presence of Citric Acid, DTPA, EDTA and Pyromellitic Acid. J. Colloid Interface Sci. 2005, 282, 370-379.

(78) Davis, K. J.; Dove, P. M.; de Yoreo, J. J. The Role of $\mathrm{Mg}^{2+}$ as an Impurity in Calcite Growth. Science 2000, 290, 1134-1137.

(79) Meyer, H. J. The Influence of Impurities on the Growth Rate of Calcite. J. Cryst. Growth 1984, 66, 639-646. 